\title{
Involvement in clubs or voluntary associations, social networks and activity generation: a path analysis
}

\author{
Pauline van den Berg $\cdot$ Theo Arentze $\cdot$ Harry Timmermans
}

Published online: 11 April 2012

(C) The Author(s) 2012. This article is published with open access at Springerlink.com

\begin{abstract}
Leisure activities have received increasing attention from travel behavior researchers over the past decade. However, these activities are often treated as a single category, neglecting their differences. Whereas most leisure activities are flexible, club activities are usually scheduled longer in advance and are more fixed in time, location and company. Hence, trip-generating properties of club activities are likely to differ from those of other leisure activities. As very little is known about involvement in clubs or voluntary associations in relation to trip generation, voluntary association activities deserve further research in relation to travel. Therefore, in this paper a path analysis is conducted, analyzing the relationships between participation in clubs or voluntary associations, trip frequencies, and social network characteristics. The analyses are based on data collected in 2011 in Eindhoven in the Netherlands in a survey among 516 respondents. The results show interesting relationships between the social context and involvement in clubs. They indicate that people become club members through their social networks, and frequent club activities increase social network size. Family oriented people were found to go less often to clubs. Club membership and the frequency of going to club activities were also found to be affected by socio-demographics, such as gender, age, education, work, presence of young children in the household and owning a season ticket for public transport.
\end{abstract}

Keywords Voluntary associations - Club activities · Travel - Social networks · Path analysis

P. van den Berg $(\bowtie) \cdot$ T. Arentze $\cdot$ H. Timmermans

Eindhoven University of Technology, P.O. Box 513, 5600 MB Eindhoven, The Netherlands

e-mail: p.e.w.v.d.berg@tue.nl

T. Arentze

e-mail: t.a.arentze@tue.nl

H. Timmermans

e-mail: h.j.p.timmermans@tue.nl 


\section{Introduction}

Over the last few decades, models of transport have started to consider individuals' needs to conduct activities as an explanation of their travel choice behavior. It has been recognized that research into leisure travel behavior is important as leisure activities are responsible for a substantial portion of travel (in terms trip frequency and travel distance) and they are an important factor of people's well being. For instance, in the Netherlands, (social) recreational travel (not including social visits) is responsible for $35 \%$ of all travel in terms of number of trips and kilometers travelled. This means an average of 1.04 trips and $11.15 \mathrm{~km}$ per person per day for these purposes.

A few studies with a special focus on leisure activities (including social activities) have been published recently (e.g., Schlich et al. 2004; Stauffacher et al. 2005; Carrasco and Miller 2006, 2009; Kemperman et al. 2006; Mokhtarian et al. 2006; Dugundji et al. 2008; Farber and Páez 2009; Tarigan and Kitamura 2009; Van den Berg et al. 2010, 2011b; Dugundji et al. 2011; LaMondia and Bhat 2011). Until recently, leisure activities have been treated as a single category, neglecting their heterogeneity. The insufficient differentiation of leisure is increasingly coming to the attention of researchers (Schlich et al. 2004). A further segmentation of leisure activities can help to improve activity-based models of transport. In this context, activities organized by clubs or voluntary association are a specific type of leisure activity which deserve further research in relation to travel. Club or voluntary association activities are usually merged with leisure or social activities, even though they differ from most leisure (and social) activities. Whereas most leisure activities are flexible, club activities are usually scheduled longer in advance and they are more fixed in time, location and company. For instance, analyzing the rhythms of travel, Schönfelder and Axhausen (2001) show that the leisure categories active sports and club meeting rhythms are fairly stable, with a relative maximum at 1 week. In addition, trips for club meetings are shorter than most other leisure trips. For example, Schlich et al. (2004) found mean trip distances for club meetings of 5.5 and $8.0 \mathrm{~km}$ for women and men respectively, versus 13.2 and $13.5 \mathrm{~km}$ for all leisure activities.

In two longitudinal diary studies of 2- and 12-weeks duration in Switzerland, Stauffacher et al. (2005) studied the motives for different leisure activities. They distinguished 15 different leisure activities, including club meetings. They showed that social contact is an important motive for club activities. They also showed descriptive statistics on mode use for the activities, indicating that around $50 \%$ of trips to club meetings are by motorized modes and $50 \%$ by bike or on foot.

Compared to transportation research, sociology has a richer history in studying involvement in voluntary associations as club membership is an important aspect of social capital and is related to the quality of life of people. A number of studies have addressed the issue of decreases in involvement in associations and its negative effect on social trust, connections with friends and relatives, and happiness. Seminal research by Putnam (2000) suggests that participation in civic and community activities has declined. Further research on this matter has generated mixed results (e.g., Paxton 1999; Rotolo 1999; Dekker and Van den Broek 2005; Fischer 2005 Van Ingen and Dekker 2011). For instance, Fischer (2005) concludes that membership in civic organizations has not declined or has declined in only a few specific types of organizations.

Paxton (1999) studied recent changes in U.S. social capital. She defined social capital as the formal and informal ties between individuals, resulting in trust, reciprocity and positive emotion. Her analyses showed some decline in a general measure of social capital, a 
decline in trust in individuals, no general decline in trust in institutions, and no decline in associations.

Van Ingen and Dekker (2011) studied people's choice for a social context (associational, individual and informal group context) for their leisure activities, including sports, artistic and cultural activities and hobbies. Their study indicates that $9 \%$ of these activities are performed in the context of a voluntary association. They found participation in associations for leisure activities to remain constant between 1975 and 2005 in absolute numbers. Participation in associations for sports was found to increase, participation in associations for hobbies was found to decrease, while participation in associations for arts and culture remained stable. They found however that a growing share of leisure activities is performed in informal groups, compared to the share of activities in voluntary associations. They did not find evidence for individualization.

Finally, Dekker and Van den Broek (2005) did not find a general decline in involvement in associations either, nor a trend towards more passive membership. Furthermore, they state that not much is known about face-to-face involvement in voluntary associations: how do members communicate and how often do they meet?

Overall, these studies do not indicate that involvement in clubs or voluntary associations is declining. However, as suggested by Dekker and Van den Broek (2005), still little is known about the frequency of participation in the context of voluntary associations, that is, the generation of leisure activities of this type and related travel. Thus, while the literature seems to indicate that the social context (company) for leisure activities is shifting toward more informal social network connections, the differences between formal groups and informal connections, and their activity-travel generation effects, are still poorly understood.

Attending to the need for a better understanding of the frequency and characteristics of social contact, the objective of this paper is to study involvement (membership) and participation (frequency) in clubs or voluntary associations, and the relationship with social network characteristics. In order to account for potential endogeneity between social network and activity generation, analysis is conducted using a path analysis approach.

The analyses are based on data collected in 2011 in Eindhoven in the Netherlands in a survey among 516 respondents. The estimated model can be used to micro-simulate involvement in voluntary associations of a population and derive assessments of travel demand generated by voluntary association activities. This will allow us to estimate more elaborate models of travel behavior.

The structure of the paper is as follows. The next section describes the conceptual considerations. "Data collection and descriptive statistics" section presents the data collection and descriptive statistics. In "Methods and results" section the path analysis results are presented. Finally, "Conclusions and discussion" section contains the conclusions and discussion.

\section{Conceptual considerations}

The goal of this study is to analyze the factors influencing the number of clubs or voluntary associations people are involved in and the factors influencing how often they go to club or association activities. Both variables are related in the sense that membership of a higher number of clubs or voluntary associations will probably result in higher frequencies of going to association activities. 
In addition, it has been recognized that the study of individuals' social network characteristics can provide new insights into the generation of leisure activities and travel involved. Individuals can be informally connected to others through friendship choices and other types of network ties, or individuals can be connected to others through formal group memberships, such as clubs or voluntary associations (Paxton 1999). Both types of social context may influence each other. For instance, club membership can be a substitute for informal social network ties. On the other hand, going to association activities can be an opportunity to make more friends. This way the frequency of going to associations can influence social network size and composition. As the causality of the relation between social network characteristics and involvement in voluntary associations is unclear, both directions should be studied.

In sociological studies, some personal and household socio-economic factors have been found to influence involvement in voluntary associations. For instance, Curtis et al. (1992) found that males, older people, higher educated people and people who work more are more likely to be a member of a voluntary association. Wright and Hyman (1958) found social status (income, education, home ownership) to have a positive effect on association membership. Males were also found to be more likely to be members of a voluntary association. They also found people with a partner and children to be more likely to be involved in voluntary associations. Note however that this study dates from 1958 and the factors influencing involvement in voluntary associations are likely to have changed since.

Using an activity-based perspective we assume that after taking care of mandatory and maintenance activities, some time is left to become involved in voluntary associations. The time available for associations is likely to be restricted by time spent on working or studying. It may also be influenced by household composition. Especially the presence of young children can lessen the need or even be a constraint for leisure activities ( $\mathrm{Lu}$ and Pas 1999; Carrasco and Miller 2006). In addition, older people are likely to have more time for club activities, which can result in more trips. However, they may be less mobile and therefore have fewer possibilities to travel to club or association activities.

Besides personal and household socio-economics, mobility characteristics may affect involvement in clubs or voluntary associations. Car ownership and public transport season ticket ownership have been found to have a positive effect on leisure travel as they offer opportunities to travel. In addition, urban density might affect involvement in clubs or voluntary associations, although Wright and Hyman (1958) found no differences in association membership between urban residence and rural non-farm residence.

\section{Data collection and descriptive statistics}

The data used for this study were collected in May 2011 in a number of neighborhoods in Eindhoven. The data collection instrument consisted of a survey on quality of life aspects in the area of residence. People aged 18 or over (which is the driving age in the Netherlands) could participate, as this is the driving age in the Netherlands. Although leisurerelated travel behavior of children is relevant as well, the survey focused on adults. The responses were describing the individual.

For the sample a stratified sampling technique was used. The city was divided into neighborhoods (based on the arrangement of the municipality), in which equal numbers of questionnaires were collected. The addresses within these neighborhoods were chosen randomly. To recruit respondents, a personal approach was employed by visiting them at home. If residents were not at home, the addresses were skipped. The visits took place at 
varying times of day, also in the evening, to prevent underrepresentation of working people. The personal approach was employed to increase respondent's participation. However, it may have caused some bias in the sample of people who were not home. In total, 516 useful questionnaires were collected.

Table 1 presents the dependent variables considered in the analysis, conform to the conceptual framework. There are two dependent variables regarding clubs or associations: the number of clubs or associations the respondent is actively involved in and the frequency of going to club or association activities.

Before measuring the number of voluntary associations involved in, respondents were asked if they were an active member of any of the following club or association categories: sports club, hobby club, choir/drama or dancing club, political party or organization, trade union or professional association, church or religious organization, (home)care organization, neighborhood association, women's organization, education or student union, nature or environmental organization, social/welfare organization or other kind of association. After this question, respondents were asked in how many clubs or voluntary associations they are actively involved. In total, 235 respondents (46\%) indicated not to be actively involved in any club or association; $158(31 \%)$ are actively involved in one club or association; $70(14 \%)$ in two clubs or associations; and $53(10 \%)$ are active members of three or more (up to eight) clubs or associations. This can be seen in Table 1.

Secondly, we asked respondents how often they go to their clubs or associations. This was measured on an ordinal scale on an aggregate level (for all clubs together). As can be seen in Table 1, out of the 516 respondents, $46 \%$ go never; $9 \%$ go once a month or less; $8 \%$ go two or three times a month; $17 \%$ go once a week; and $20 \%$ indicated to go several times per week. This measure is especially relevant from a transportation point of view, as

Table 1 Dependent variables $(N=516$ respondents)

\begin{tabular}{|c|c|c|}
\hline & $N$ & $\%$ \\
\hline \multicolumn{3}{|l|}{ Number of clubs or associations } \\
\hline 0 & 235 & 46 \\
\hline 1 & 158 & 31 \\
\hline 2 & 70 & 14 \\
\hline 3 & 31 & 6 \\
\hline 4 & 12 & 2 \\
\hline 5 & 5 & 1 \\
\hline 6 & 3 & 1 \\
\hline 7 & 1 & 0 \\
\hline 8 & 1 & 0 \\
\hline \multicolumn{3}{|c|}{ Frequency of going to association } \\
\hline Never & 237 & 46 \\
\hline Once a month or less & 46 & 9 \\
\hline 2 or 3 times per month & 40 & 8 \\
\hline Once a week & 90 & 17 \\
\hline \multirow[t]{2}{*}{ Several times per week } & 103 & 20 \\
\hline & Mean & St. dev. \\
\hline \# social network members & 27.17 & 34.84 \\
\hline Share of relatives in network & 0.50 & 0.26 \\
\hline
\end{tabular}


it directly indicates the travel frequency for the purpose of club or association activities. In the model this variable is treated as a continuous variable that represents the frequency per month. The categories were therefore recoded into $0,1,2.5,4$ and 10 times per month. Unfortunately, the dataset does not provide information on the frequency by association, or detailed information on other travel aspects of association activities, such as location, distance, or transport mode used.

There are two variables regarding social network characteristics: social network size and the share of relatives in the social network. These variables were measured using the following question: Think about the people you feel very close to and somewhat close to. Very close are people with whom you discuss important matters, or regularly keep in touch with, or that are there for you if you need help.

Somewhat close are people that are more than just casual acquaintances, but not very close. For both very close and somewhat close respondents were asked the number of direct relatives, other relatives, colleagues or fellow students, club or association members, neighbors and other friends.

This method used to gather the characteristics of the respondent's social networks is known as the summation method (see McCarty et al. 2000 for details). The total number of very close and somewhat close ties is used as the measure for social network size. On average, the respondents have a network size of 27.17 alters, which is comparable to other studies that used the same name generators (Hogan et al. 2007; Van den Berg et al. 2009). The share of relatives is the percentage of direct and other relatives in the total social network (as opposed to colleagues or fellow students, club or association members, neighbors and other friends).

Several background variables were collected in the questionnaire. Based on an examination of different transformations and levels of explanatory variables, the following explanatory variables are used in the analysis: gender (male vs. female), age, high education (defined as bachelor degree or higher), full-time work or study, high income (net income more than $3000 €$ per month), the presence of children under 6 years of age in the household (yes or no), living in suburban area (density of 500-1500 addresses per $\mathrm{km}^{2}$ ), the number of cars in the household, and season ticket for public transport (for either bus/ metro or train, or both). Table 2 shows the descriptive statistics of the explanatory variables that are considered in this study. The sample is fairly representative of the Dutch population, although higher educated people are somewhat overrepresented.

\section{Methods and results}

As indicated before, the goal of the present paper is to analyze the number of clubs or voluntary associations people are involved in and how often they go to association activities, as well as the relationships between social network characteristics and association memberships and frequency.

Using path analysis the effects of the explanatory variables on the dependent variables, as well as the relationships between the dependent variables can be estimated simultaneously. Path analysis is a special case of structural equation modeling (SEM). Whereas SEM can deal with measured (or observed) variables and latent variables (also known as factors, constructs or unobserved variables), path analysis deals only with measured variables. In this study we use path analysis, because the variables all refer to characteristics or behavior that is observed. 
Table 2 Explanatory variables considered in the analysis $(N=516$ respondents $)$

\begin{tabular}{|c|c|c|c|}
\hline & $\begin{array}{l}\text { Sample } \\
N\end{array}$ & $\begin{array}{l}\text { Sample } \\
\%\end{array}$ & $\begin{array}{l}\text { Netherlands } \\
\%\end{array}$ \\
\hline Gender (male) & 249 & 48 & 49 \\
\hline High education (BSc or higher) & 214 & 42 & 28 \\
\hline Full time work or study & 200 & 39 & 43 \\
\hline $\begin{array}{l}\text { High income }(>3000 € \text {, per month } \\
\text { after tax })\end{array}$ & 182 & 35 & 37 \\
\hline Child(ren) under six in household & 98 & 19 & 11 \\
\hline $\begin{array}{l}\text { Suburban }(500-1500 \text { addresses } \\
\left.\text { per } \mathrm{km}^{2}\right)\end{array}$ & 128 & 25 & 39 \\
\hline \multirow[t]{2}{*}{ Season ticket public transport } & 173 & 34 & \\
\hline & Mean & St. dev. & Mean \\
\hline Age & 45.15 & 15.91 & 40.1 \\
\hline \# cars in the household & 1.19 & 0.69 & 1.05 \\
\hline
\end{tabular}

The path analysis model was estimated using the statistical software package LISREL (Jöreskog and Sörbom 2001). Despite non-normality in the data, the maximum likelihood method was used to estimate the models.

Although maximum likelihood estimation is fairly robust against violations of multivariate normality for sufficiently large sample sizes (Golob 2001), this may cause some bias in the standard errors and goodness-of-fit estimates.

A number of different model specifications were tested, with different directions between the endogenous variables and different (transformations and levels of) explanatory variables. The exogenous socio-demographic variables are allowed to be correlated in the model. Variables that did not significantly affect any of the endogenous variables, such as car ownership, household size and the presence of children older than 6 , were removed. The unstandardized coefficients and $t$ statistics of direct and total effects of the final model that are significant at the 0.1 significance level are shown in Table 3 . The total effects are the direct effects ( $X$ causes $Y$ ) plus indirect effects ( $X$ causes $Z$, which in turn causes $Y$ ).

Effects between the endogenous variables

As indicated, different model structures were tested regarding the relationships between the four endogenous variables. The modelling results indicate that social network size has a negative effect on the share of relatives in the social network. This suggests that if one's social network size increases with one member, the percentage of non-relatives increases with $2 \%$. This is a plausible finding, as the number of relatives in the social network is more or less fixed, and the number of other network members (such as friends or fellow club members) is more flexible.

Social network size is found to have a positive effect on the number of clubs or voluntary associations people are actively involved in. However, the effect is small: for every social network member the number of clubs increases with 0.004 . Regarding the relationship between social network size and the frequency of going to association activities the results show that going more often to club or association activities, is likely to result in a larger social network: with every additional club visit per month the network 
Table 3 Path analysis model estimates (unstandardized effects)

\begin{tabular}{|c|c|c|c|c|c|c|c|c|}
\hline \multirow[t]{3}{*}{ From } & \multicolumn{8}{|l|}{ To } \\
\hline & \multicolumn{2}{|c|}{ Network size } & \multicolumn{2}{|c|}{ Share of relatives } & \multicolumn{2}{|c|}{$\begin{array}{l}\text { Number of } \\
\text { associations }\end{array}$} & \multicolumn{2}{|c|}{$\begin{array}{l}\text { Frequency to } \\
\text { associations }\end{array}$} \\
\hline & Direct & Total & Direct & Total & Direct & Total & Direct & Total \\
\hline \multicolumn{9}{|c|}{ Effects between the endogenous variables } \\
\hline Network size & & 0.012 & -0.002 & -0.002 & 0.004 & 0.004 & & 0.009 \\
\hline$t$ statistic & & 3.004 & -5.199 & -5.610 & 2.557 & 2.548 & & 3.460 \\
\hline Share of relatives & & -2.609 & & 0.005 & & -0.011 & -1.961 & -1.984 \\
\hline$t$ statistic & & -2.453 & & 2.446 & & -2.072 & -3.355 & -3.347 \\
\hline \# associations & & 1.747 & -0.040 & -0.043 & & 0.007 & 1.235 & 1.328 \\
\hline$t$ statistic & & 2.867 & -4.376 & -4.678 & & 2.479 & 9.951 & 10.688 \\
\hline Frequency to ass. & 1.315 & 1.331 & & -0.002 & & 0.006 & & 0.012 \\
\hline$t$ statistic & 2.956 & 2.935 & & -2.830 & & 2.470 & & 3.004 \\
\hline \multicolumn{9}{|c|}{ Effects of explanatory variables } \\
\hline Male & & 1.356 & & -0.017 & 0.375 & 0.380 & 0.527 & 1.031 \\
\hline$t$ statistic & & 2.152 & & -2.922 & 3.394 & 3.419 & 1.819 & 3.164 \\
\hline Age & & -0.044 & 0.003 & 0.003 & & 0.000 & -0.028 & -0.034 \\
\hline$t$ statistic & & -2.255 & 4.145 & 4.239 & & -2.026 & -2.927 & -3.520 \\
\hline High education & & -0.984 & & -0.008 & 0.254 & 0.250 & -1.073 & -0.748 \\
\hline$t$ statistic & & -1.815 & & -1.600 & 2.398 & 2.341 & -3.660 & -2.289 \\
\hline Full time work & & -0.340 & & 0.008 & -0.195 & -0.196 & & -0.258 \\
\hline$t$ statistic & & -1.491 & & 1.631 & -1.740 & -1.739 & & -1.717 \\
\hline High income & 6.773 & 6.956 & -0.040 & -0.053 & & 0.029 & & 0.139 \\
\hline$t$ statistic & 2.103 & 2.133 & -1.799 & -2.285 & & 1.654 & & 2.220 \\
\hline Children under 6 & & -1.706 & & 0.013 & -0.261 & -0.269 & -0.939 & -1.297 \\
\hline$t$ statistic & & -2.090 & & 2.093 & -1.929 & -1.967 & -2.395 & -2.984 \\
\hline Suburban & 6.570 & 6.646 & & -0.012 & & 0.028 & & 0.058 \\
\hline$t$ statistic & 1.846 & 1.846 & & -1.753 & & 1.495 & & 1.629 \\
\hline Season ticket & & 2.044 & -0.044 & -0.067 & 0.489 & 0.498 & 0.807 & 1.554 \\
\hline$t$ statistic & & 2.455 & -1.907 & -2.893 & 4.415 & 4.458 & 2.588 & 4.503 \\
\hline$R^{2}$ & 0.060 & & 0.156 & & 0.114 & & 0.301 & \\
\hline$R^{2}$ reduced & 0.019 & & 0.055 & & 0.088 & & 0.101 & \\
\hline
\end{tabular}

size increases with 1.3 members on average. This indicates that people meet new friends when going to club or association activities.

A larger share of relatives in the social network is found to negatively influence the frequency of going to association activities. This indicates that people who are more family oriented are less likely to go to club activities. The number of clubs or associations actively involved in is found to have a negative effect on the share of relatives in the social network. This is probably related to the fact that club members on average have a larger social network (consisting of more non-relatives, such as fellow club members).

Finally, as expected, the number of clubs people are involved in has a positive effect on the frequency of going to a club activity: with every additional club membership the frequency of going to a club increases with approximately 1.2 visits per month on average. 
This indicates that clubs and voluntary associations generate travel. The direct effects between the endogenous variables can be seen in Fig. 1.

\section{Effects of explanatory variables on social network size and composition}

Next, the effects of the explanatory variables on social network size and composition are discussed. Only four explanatory variables are found to significantly affect the two social network characteristics in the model. Age is found to have a positive effect on the share of relatives in the social network, indicating that older people have larger proportions of relatives in their social network.

High income is found to have a positive effect on social network size and results in 6.8 more network members compared to people with lower income. High income has a negative effect on the share of relatives in the social network. This suggests that people with a higher income are likely to have more friends.

The results suggest that people living in suburban areas on average have 6.6 more people in their social network compared to people living in urban areas. This is in line with findings from Van den Berg et al. (2011a) suggesting that low urban density is has a positive effect on social network size. This may indicate that in lower density areas traditionally strong local networks still exist (Aoki et al. 1996).

Finally, the results show that season ticket ownership results in a $4 \%$ smaller share of relatives in the social network. The explanation for this is unclear.

Effects of explanatory variables on the number of clubs or associations

The results in Table 3 indicate that men are likely to be involved in more clubs or associations than women. This is in line with findings from earlier studies (e.g., Wright and Hyman 1958; Curtis et al. 1992). If all other variables are evaluated at zero, being male results in 0.38 more clubs. In contrast to earlier findings (e.g., Curtis et al. 1992), age is not found to significantly affect the number clubs or voluntary associations.

High education is found to have a positive effect on the number of clubs or associations. It results in 0.25 more club memberships. This finding is in line with Wright and Hyman (1958) and Curtis et al. (1992).

We find full time work or study to result in 0.2 fewer clubs or association memberships. This can be explained by the fact that full time workers or student have less time available for clubs or associations. This finding is however in contrast with Curtis et al. (1992), who analyzed data on voluntary association membership from 1981 to 1983 from 15 countries and found a positive effect of work status on club membership. The difference between

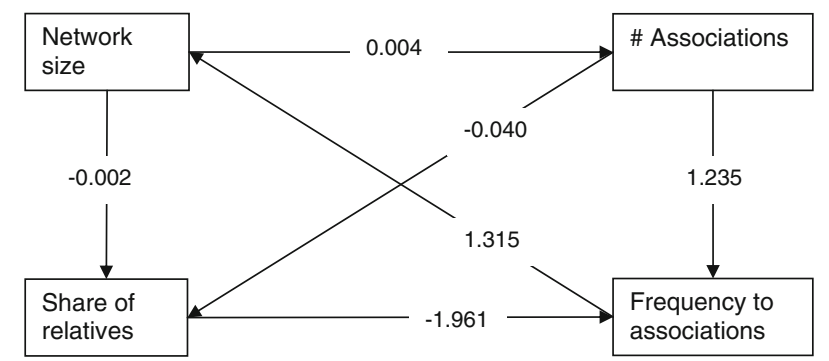

Fig. 1 Direct effects between endogenous variables 
their findings and ours is probably related to the fact that people's time use patterns have changed over the last decades.

We do not find income to significantly affect the number of clubs people are actively involved in. This finding seems in contrast with Wright and Hyman (1958) who found a positive effect for income on involvement in voluntary associations. Note however that this difference may be related to the fact that this study dates from 1958.

The presence of young children (under 6) is found to have a negative effect on the number of clubs or associations. It results in 0.26 fewer club memberships. This was expected, as the presence of young children can lessen the need or be a constraint for being involved in associations. However, Wright and Hyman (1958) found people with a partner and people with children to be more likely to be members of a voluntary association. Again this difference may be related to the fact that the factors influencing involvement in voluntary associations may have changed since 1958.

Urban density is not found to affect the number of clubs people are actively involved in. With regard to the mobility characteristics we find season ticket owners to be involved in 0.5 more voluntary associations or clubs, whereas the number of cars in the household has no significant effect. It is not clear what the explanation of this effect is. It might be explained either by the fact that ownership of a season ticket reduces the variable costs of making the trips or that the variable is correlated with club membership through some other third variable.

\section{Effects of explanatory variables on travel frequency to association activities}

The last endogenous variable in the analysis concerns how often people go to a club or association. We find that men are likely to go approximately 0.53 times per month more often to club or association activities than women.

For age we find a negative effect, indicating that older people go less often to a club or voluntary association activity. The effect is small: every 3 years increased in age, results in one club activity per year fewer. The finding of a negative effect is in contrast with findings from Curtis et al. (1992), who found involvement in voluntary associations to increase with age. However, their definition of voluntary associations differs from ours as they do not include sports or hobby clubs, in which young people are more actively involved. This may explain the different finding.

Whereas high education was found to have a positive effect on the number of clubs or associations, it has a negative effect on the frequency of trips to a club or voluntary association: it results in 1.1 fewer club activities per month. Neither full time work or study nor income is found to significantly affect the frequency of going to a club or association.

People with young children in their household are found to go almost once a month less often to club activities. This can be explained by time constraints, assuming that the presence of children implies more maintenance activities and thus less time for club activities (Hogan et al. 2007).

Finally, with regard to season ticket ownership we find a positive effect on the frequency of going to voluntary associations or clubs. It results in 0.8 more trips per month. This indicates that season ticket ownership is a mobility tool that makes it easier to go to club activities. The direct effects of the explanatory variables are shown in Fig. 2.

Table 4 shows the goodness-of-fit of the model. Several measures are reported. The primary measure of parsimony is the degrees of freedom of the model. This is equal to the difference between the number of free parameters in the model and the number of known quantities. The number of known quantities is equal to the number of free elements in the 


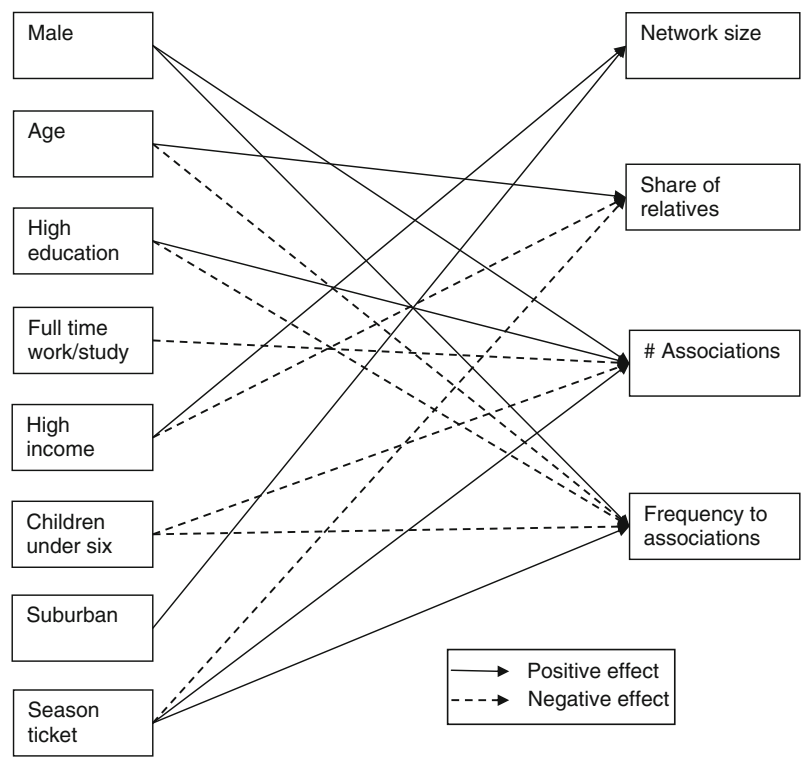

Fig. 2 Direct effects of exogenous on endogenous variables

Table 4 Goodness-of-fit of the model

\begin{tabular}{ll}
\hline Degrees of freedom & 17 \\
Minimum fit function $\chi^{2}$ & 9.504 \\
$\chi^{2}$ /degrees of freedom & 0.559 \\
RMSEA & 0.000 \\
Model AIC & 131.475 \\
Saturated AIC & 156.000 \\
Normed fit index & 0.988 \\
\hline
\end{tabular}

variance-covariance matrix of the variables. A saturated (or just-identified) model has zero degrees of freedom and fits perfectly (Golob 2001).

The $\chi^{2}$ statistic is given by the product of the optimized fitting function and the sample size (Golob 2001). Chi Square divided by the model degrees of freedom has been suggested as a useful measure and rules of thumb suggest that for correct models this measure should be smaller than 2 (Golob 2001) or at least smaller than 5, but preferably around 1 (Washington et al. 2003). According to this rule of thumb, the model has a good fit with a value of 0.559 .

Another goodness-of-fit measure which is based on the $\chi^{2}$ is the root mean square error of approximation (RMSEA), which measures the discrepancy per degree of freedom. The value should preferably be less than 0.05 (Golob 2001).

The model's Akaike information criterion (AIC) should be close to the value for the saturated model. Finally, the value of the normed fit index compares the fitted model to the saturated model. It can take on values between 0 and 1 . The value should be close to 1 as this indicates a close fit to the saturated model (Washington et al. 2003).

Based on these rules of thumb, Table 4 suggests that the model provides a good fit for the data. 


\section{Conclusions and discussion}

It has long been recognized in transportation research that travel is induced by activities. Leisure activities have received increasing attention from travel behavior researchers over the past decade, as they are responsible for a large and growing portion of travel. However, leisure activities are often treated as a single category, neglecting their differences. The involvement in voluntary association activities has received hardly any attention. Therefore, this paper aims at increasing our understanding of the factors influencing involvement in voluntary associations and the frequency of travelling to association activities.

Based on survey data collected in the Netherlands a path analysis was conducted, analyzing the number of clubs or voluntary associations people are actively involved in and how often they travel to association activities, as well as social network size and the share of relatives in the social network. The exogenous variables in the model are personal and household characteristics and mobility characteristics.

Regarding the endogenous variables, the results indicate that social network size has a negative effect on the share of relatives in the social network and a positive effect on the number of clubs or voluntary associations people are actively involved in. This suggests that through their social networks, people get in contact with associations and become members. This also suggests that there is no substitution effect, but rather complementarity between formal and informal ties. The results further show that people who go more often to club or association activities, have a larger social network. This indicates that new friendships are formed through association activities. A larger share of relatives in the social network is found to have a negative effect on the frequency of going to association activities, after correcting for the number of clubs/associations the individual is a member of. The number of clubs or associations is found to have a negative effect on the share of relatives in the social network. Finally, the number of clubs people are involved in, has a positive effect on the frequency of going to a club activity.

Social network size was found to be positively affected by income and living in suburban areas. The share of relatives in the social network was found to be positively affected by age and negatively affected by income.

The number of clubs or associations is positively affected by gender (male), high education and public transport season ticket ownership. Negative effects were found for working or studying full time and the presence of young children in the household.

Regarding the travel frequency to club or association activities positive effects were found for being male, living in a larger household, and season ticket ownership. Negative effects were found for age, high education, and the presence of children under 6 years of age.

Several questions for future research remain. The focus of this study was primarily on involvement in voluntary associations, stating that this can result in travel demand. However, we did not differentiate between different types of clubs or voluntary associations, as the data did not include information on travel frequency per type of organization. In addition, the sample contained only adults. For future research, it would be interesting to also examine children's involvement in club activities. Moreover, for a more detailed analysis of travel demand, additional information on the travel aspects of associational activities (e.g., type of location, distance, transport mode, time of day, day of the week, etc.) is relevant.

Nevertheless, this study adds to the understanding of club activities in relation to travel demand, which has received very little attention in academic research. The estimated model can be used in micro-simulations of leisure travel demand. In an agent-based model, 
characteristics of personal social networks can be added as links between individual agents, who plan and perform different types of leisure activities together. Ideally, a leisure activity generation model should incorporate the ego's social network's size and composition, including formal groups as well as informal connections. This study suggests that activity-based models can be improved with respect to leisure activities, by a further segmentation of these activities and by giving more attention to the social context of these activities.

Open Access This article is distributed under the terms of the Creative Commons Attribution License which permits any use, distribution, and reproduction in any medium, provided the original author(s) and the source are credited.

\section{References}

Aoki, R., Ohno, Y., Tamakoshi, A., Kawakami, N., Nagai, M., Hashimoto, S., Ikari, A., Shimizu, H., Sakata, K., Kawamura, T., Wakai, K., Senda, M.: Lifestyle determinants for social activity levels among the Japanese elderly. Arch. Gerontol. Geriatr. 22, 271-286 (1996)

Carrasco, J.A., Miller, E.J.: Exploring the propensity to perform social activities: a social networks approach. Transportation 33, 463-480 (2006)

Carrasco, J.A., Miller, E.J.: The social dimension in action. A multilevel, personal networks model of social activity frequency between individuals. Transp. Res. A 43, 90-104 (2009)

Curtis, J., Grabb, E., Baer, D.: Voluntary association membership in fifteen countries: a comparative analysis. Am. Sociol. Rev. 57, 139-152 (1992)

Dekker, P., van den Broek, A.: Involvement in voluntary associations in North America and Western Europe: trends and correlates 1981-2000. J. Civ. Soc. 1, 45-59 (2005)

Dugundji, E.R., Páez, A., Arentze, T.A.: Social networks, choices, mobility, and travel. Environ. Plan. B 35, 956-960 (2008)

Dugundji, E.R., Páez, A., Arentze, T.A., Walker, J.L., with contributions from Carrasco, J.A., Marchal, F., Nakanishi, H.: Transportation and social interactions. Transp. Res. A 45, 239-247 (2011)

Farber, S., Páez, A.: My car, my friends, and me: a preliminary analysis of automobility and social activity participation. J. Transp. Geogr. 17, 216-225 (2009)

Fischer, C.S.: Bowling alone: what's the score? Soc. Netw. 27, 155-167 (2005)

Golob, T.: Structural equation modeling for travel behavior research. Transp. Res. B 37, 1-25 (2001)

Hogan, B., Carrasco, J.A., Wellman, B.: Visualizing personal networks: working with participant-aided sociograms. Field Methods 19, 116-144 (2007)

Jöreskog, K., Sörbom, D.: LISREL 8. User's reference guide. Scientific Software International, Chicago (2001)

Kemperman, A.D.A.M., Arentze, T.A., Timmermans, H.J.P.: Social commitments and activity-travel scheduling decisions. In: Proceedings of the 85th Annual Meeting of the Transportation Research Board, Washington (2006)

LaMondia, J., Bhat, C.: A conceptual and methodological framework of leisure activity loyalty accommodating the travel context. In: Proceedings of the 90th Annual Meeting of the Transportation Research Board, Washington (2011)

Lu, X., Pas, E.: Socio-demographics, activity participation and travel behavior. Transp. Res. A 33, 1-18 (1999)

McCarty, C., Killworth, P.D., Bernard, H.R., Johnsen, E.C., Shelley, G.A.: Comparing two methods for estimating network size. Hum. Organ. 60, 28-39 (2000)

Mokhtarian, P.L., Salomon, I., Handy, S.: The impacts of ICT on leisure activities and travel: a conceptual exploration. Transportation 33, 263-289 (2006)

Paxton, P.: Is social capital declining in the United States? A multiple indicator assessment. Am. J. Sociol. 105, 88-127 (1999)

Putnam, R.: Bowling alone. The collapse and revival of American community. Simon \& Schuster, New York (2000)

Rotolo, T.: Trends in voluntary association participation. Nonprofit Volunt. Sect. Q. 28, 199-212 (1999)

Schlich, R., Schönfelder, S., Hanson, S., Axhausen, K.W.: Structures of leisure travel: temporal and spatial variability. Transp. Rev. 24, 219-237 (2004) 
Schönfelder, S., Axhausen, K.W.: Analysing the rhythms of travel using survival analysis. In: Proceedings of the 80th TRB Annual Meeting, Washington (2001)

Stauffacher, M., Schlich, R., Axhausen, K.W., Scholz, R.W.: The diversity of travel behaviour: motives and social interactions in leisure time activities. Arbeitsberichte Verkehr und Raumplanung. 30x, IVT, ETH Zürich (2005)

Tarigan, A., Kitamura, R.: Week-to-week leisure trip frequency and its variability transportation research record. Transp. Res. Rec. 2135, 43-51 (2009)

Van den Berg, P.E.W., Arentze, T.A., Timmermans, H.J.P.: Size and composition of ego-centered social networks and their effect on geographical distance and contact frequency. Transp. Res. Rec. 2135, 1-9 (2009)

Van den Berg, P.E.W., Arentze, T.A., Timmermans, H.J.P.: Location-type choice for face-to-face social activities and its effect on travel behavior. Environ. Plan. B 37, 1057-1075 (2010)

Van den Berg, P.E.W., Arentze, T.A., Timmermans, H.J.P.: A path analysis of social networks, ICT use and social activity-travel patterns. In: Proceedings Invited Workshop Frontiers in Transportation: Social Networks and Travel, Niagara-on-the-Lake (2011a)

Van den Berg, P.E.W., Arentze, T.A., Timmermans, H.J.P.: Estimating social travel demand of senior citizens in the Netherlands. J. Transp. Geogr. 19, 323-331 (2011)

Van Ingen, E., Dekker, P.: Dissolution of associational life? Testing the individualization and informalization hypotheses on leisure activities in the Netherlands between 1975 and 2005. Soc. Indic. Res. 100, 209-224 (2011)

Washington, S., Karlaftis, M., Mannering, F.: Statistical and econometric methods for transportation data analysis. Chapman \& Hall, Washington (2003)

Wright, C., Hyman, H.: Voluntary association memberships of American adults: evidence from national sample surveys. Am. Sociol. Rev. 23, 284-294 (1958)

\section{Author Biographies}

Pauline van den Berg is a $\mathrm{PhD}$ student at the Urban Planning Group at the Eindhoven University of Technology. She holds a MSc degree in Cultural Anthropology from the Catholic University of Nijmegen and a MSc degree in Architecture, Building and Planning from the Eindhoven University of Technology. Her research interests concern human behaviour and its social and cultural context, urban and transport planning, activity-travel behaviour and data collection techniques.

Theo Arentze is an Associate Professor in the Urban Planning group at the Eindhoven University of Technology. He holds a $\mathrm{PhD}$ from the same University and a MSc in Cognitive Science/Artificial Intelligence from the Psychology faculty at Groningen University. His main fields of expertise and current research interests are activity-based models of travel demand, integrated land-use and transport models, discrete choice models, experimental and survey methods, agent-based models and micro-simulation systems, and decision support systems with applications in urban and transport planning.

Harry Timmermans is chaired Professor of the Urban Planning Group at the Eindhoven University of Technology. He studied at the Catholic University of Nijmegen and holds a PhD degree in Geography/ Urban and Regional Planning. His main research interests concern the study of human choice processes, mathematical modelling of urban systems and spatial interaction and choice patterns and the development of decision support and expert systems for application in urban and transport planning. 